\title{
Acetate Facilitated Nickel Catalyzed Coupling of Aryl Chlorides and Alkyl Thiols
}

\author{
Regina M. Oechsner, J. Philipp Wagner,* and Ivana Fleischer*
}

Institute of Organic Chemistry, Faculty of Mathematics and Natural Sciences, Eberhard Karls University Tübingen, Auf der Morgenstelle 18, 72076 Tübingen, Germany, E-mail: ivana.fleischer@uni-tuebingen.de

\begin{abstract}
We report a mild, fast and convenient catalytic system for the coupling of aryl chlorides with primary, secondary, as well as previously challenging tertiary alkyl thiols using an air-stable nickel(II) precatayst in combination with the low-cost base potassium acetate at room temperature. This new catalytic system tolerates a variety of functional groups and enables the generation of thioethers for a wide range of substrates, including pharmaceutical compounds in excellent yields. Chemoselective functionalization of disubstituted substrates was demonstrated. Kinetic and NMR-studies, as well as DFT computations support a $\mathrm{Ni}(0) / \mathrm{Ni}(\mathrm{II})$ catalytic cycle and identify the oxidative addition product as the resting state. Acetate coordination and subsequent acetate facilitated formation of a thiolate complex via internal deprotonation play a key role in the catalytic cycle.
\end{abstract}

\section{INTRODUCTION}

The metal catalyzed C-S cross-coupling of aryl (pseudo)halides and thiols under basic conditions, known as Migita reaction, provides an efficient access to thioethers. ${ }^{1}$ The more lipophilic bioisosters of ethers are an attractive structural motif in pharmaceutical compounds, agrochemicals and materials design. ${ }^{2}$ Most academic research in the past focused on palladium catalyzed reactions ${ }^{3}$ and the same was true for industrial applications, ${ }^{4}$ but low-cost nickel-catalysts can replace the precious metal. This, as well as its intriguing and versatile reactivity patterns, ${ }^{5}$ are the reason why nickel has evolved into an intensively researched and popular metal for homogeneous catalysis.

While most nickel-catalyzed C-S couplings were developed for the transformation of more reactive aryl bromides and iodides, ${ }^{6}$ the reactions of aryl chlorides remained rare until recently (Scheme 1a). ${ }^{7}$ Aryl chlorides are comparatively more challenging to couple, but they are readily accessible compounds with a vast range of commercially available substrates, which renders them invaluable for organic synthesis. Apart from few exceptions such as the trifluorothiomethylation by Schoenebeck and co-workers, ${ }^{7 b}$ the scope of nickelcatalyzed couplings of aryl chlorides is often limited, higher catalyst loadings and temperatures, stoichiometric additives or sensitive organometallic bases are required. The latter was also the case in our report on the coupling of aryl chlorides with thiols in the presence of organomagnesium or -zinc reagents as bases and activating agents. ${ }^{8}$ Primary and secondary alkyl thiols were coupled efficiently, but tertiary thiols reacted with low yields.

The coupling of tertiary thiols remains a challenge in nickel catalysis, regardless of the employed coupling partner. ${ }^{9}$ It is performed under harsh conditions in most cases and typically, only few substrates are shown, without systematic investigation. Notable exceptions are the recent report on the coupling of aryl bromides with a Ni-diimine catalyst, by Stefan and co-workers, ${ }^{9 \mathrm{k}}$ and the work by Morandi and co-workers on metathesis of thioanisols. ${ }^{9 \mathrm{i}}$

Nevertheless, to the best of our knowledge, there is no published efficient coupling of aryl chlorides and tertiary alkyl thiols with high yields under mild reaction conditions. Therefore, our goal was to develop a general method for the nickel-catalyzed coupling of aryl chlorides with primary, secondary and especially tertiary aliphatic thiols. We achieved this by employing the precatalyst (Xantphos)Ni(o-tolyl) Cl (C1; Xantphos $=(9,9-D i m e t h y l-9 H$-xanthene-4,5-diyl $)$ bis(diphenylphosphane)), first reported by Jamison ${ }^{10}$ as air-stable, easily synthesized $\mathrm{Ni}(\mathrm{II})$ precursor, ${ }^{11}$ together with potassium acetate as low-cost and air stable base at room temperature (Scheme 1b). We present the results of our investigation on the substrate scope together with mechanistic studies, which uncovered the role of acetate in the catalytic cycle.

Scheme 1. Current challenges for the nickel-catalyzed C-S cross-coupling and our approach to tackle them

a) General: Ni-Catalyzed C-S Coupling - Challenges

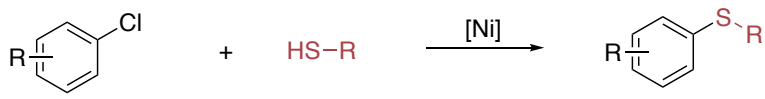

Challenge 1:

$\mathrm{ArCl}$ as substrate

- high $B D E$ of $\mathrm{C}-\mathrm{Cl}$ bond

- less reactive

- but available and cheap • unexplored

b) This Work: Acetate $=$ Key to Success

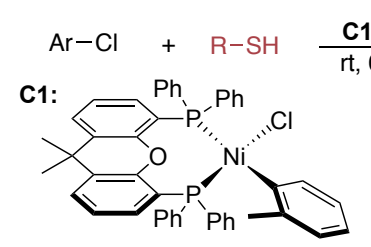

$\underset{\mathrm{rt}, 0.5-2 \mathrm{~h}}{\mathrm{C} 1, \mathrm{KOAC}} \mathrm{Ar}-\mathrm{SR}$

$\checkmark$ mild conditions

$\checkmark$ fast reaction

$\checkmark 1^{\circ}, 2^{\circ}, 3^{\circ}$ thiols

$\checkmark$ broad scope

$\checkmark$ mechanistic investigations 


\section{RESULTS AND DISCUSSION}

We began our investigation with the overall goal to find a simple and economical catalytic system to render air-sensitive transmetalation reagents and high temperatures redundant, by using precatalyst $\mathbf{C 1}$ and examining various bases (Table 1 and Table S1 in the SI). At first, the easier to couple secondary cyclohexanethiol (2a) and aryl chloride 1a were tested. To our surprise, a large variety of screened bases were successful in the cross-coupling at $50{ }^{\circ} \mathrm{C}$, generating thioether 3aa in low to moderate yields (entries 1-11). Sodium acetate could be identified as suitable base for the $\mathrm{C}$-S cross-coupling providing a high yield of 3aa (entry 12).

Table 1. Base screening for the coupling of the aryl chloride 1 a with cyclohexanethiol $2 a^{a}$

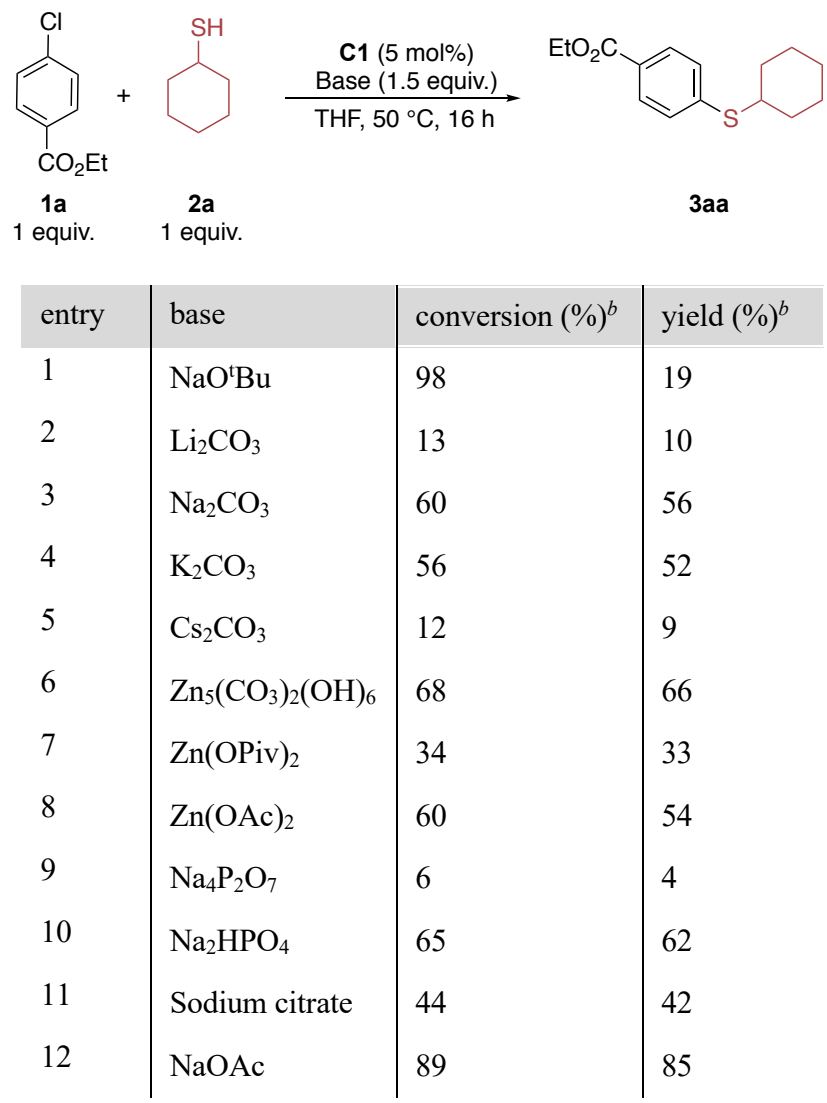

${ }^{a}$ Reaction conditions: ethyl 4-chlorobenzoate (350 $\mu \mathrm{mol}$, 1.0 equiv.), cyclohexanethiol (350 $\mu \mathrm{mol}, 1.0$ equiv.), base (1.5 equiv.), C1 (5 mol\%), THF ( $1 \mathrm{~mL}), 50{ }^{\circ} \mathrm{C}, 16$ h. ${ }^{b}$ GC-FID yields using pentadecane as internal standard.

Intrigued by the efficiency of sodium acetate we continued screening different counterions in the arylation of the more challenging adamantanethiol (2b) at room temperature (Table 2 ). While no or low reactivity was observed after $2 \mathrm{~h}$ using lithium and sodium acetates (entries 1, 3), potassium and caesium acetates showed excellent performance (entries 5, 6). A prolonged reaction time of $16 \mathrm{~h}$ led to increased yield with sodium acetate, while lithium acetate still performed poorly (entries 2, 4). Low-cost potassium acetate was chosen as optimal base over the caesium salt for further optimization of the reaction conditions (temperature, catalyst loading and substrate equivalents; see SI tables S2-S4). Upon optimization, 1 equiv. of aryl halide, 1.1 equiv. of thiol, $5 \mathrm{~mol} \% \mathrm{C1}$,
1.5 equiv. of KOAc in THF at room temperature were identified as ideal reaction conditions.

Table 2. Comparison of acetates in the coupling of the aryl chloride 1a with tertiary thiol $2 \mathbf{b}^{a}$

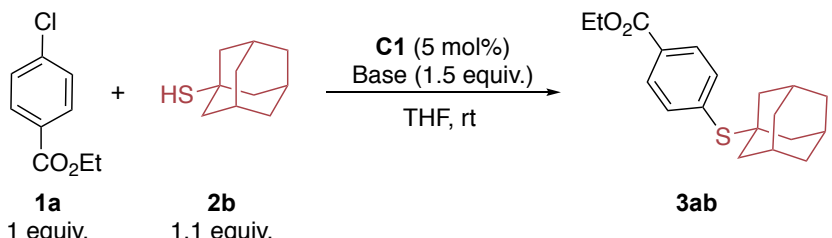

\begin{tabular}{l|l|l|l|l} 
entry & base & time $(\mathrm{h})$ & conversion $(\%)^{\mathrm{b}}$ & yield $(\%)^{b}$ \\
1 & LiOAc & 2 & 4 & 0 \\
2 & LiOAc & 16 & 5 & 2 \\
3 & NaOAc & 2 & 20 & 14 \\
4 & NaOAc & 16 & 86 & 83 \\
5 & KOAc & 2 & 95 & 95 \\
6 & CsOAc & 2 & 95 & 93
\end{tabular}

${ }^{a}$ Reaction conditions: ethyl 4-chlorobenzoate $(350 \mu \mathrm{mol}$, 1.0 equiv.), adamantanethiol (385 $\mu \mathrm{mol}, 1.1$ equiv.), acetate (1.5 equiv.), C1 (5 mol\%), THF ( $1 \mathrm{~mL})$, rt. $^{b} \mathrm{GC}$-FID yields using pentadecane as internal standard.

Subsequently, the substrate scope as well as functional group tolerance were explored with potassium acetate under optimized conditions. First, adamantanethiol was used as benchmark substrate to test a variety of aryl chlorides (Table 3). A wide range of electron-neutral, electron-rich and electrondeficient meta- and para-substituted aryl chloride derivatives could be coupled in good to excellent yields. Various functional groups like ethers $\mathbf{3 e b}$, ketones $\mathbf{3} \mathbf{f b}$, esters $\mathbf{3} \mathbf{a b}$, amides $\mathbf{3 j b}$ and nitriles $\mathbf{3 n b}$ were tolerated. The sulfone $\mathbf{4} \mathbf{c b}$ was obtained after oxidation of $\mathbf{3} \mathbf{c b}$ with $m$-CPBA. For ortho-substituents, only low yields of 3rb could be obtained (15\%) by employing the aryl chloride, whereas the bromide was converted in excellent yield $(87 \%)$, showcasing the more facile oxidative addition. The low reactivity of chloride $\mathbf{1 r}$ was used for a selective functionalization of dichloride $1 \mathbf{s}$ to furnish monothioether $\mathbf{3 s b}$ by steric discrimination.

Heterocycles, which are important motifs in pharmaceuticals and agrochemicals, like pyridine, quinoline, indole, thiazole, dioxole, phenothiazine or $4 H$-chromen-4-one were tolerated and afforded the corresponding products $3 \mathbf{u b}-\mathbf{B b}$ in good to excellent yields. Moreover, the successful sulfenylation of pharmaceutically active compounds or their derivatives like Loratidin (3Cb, allergy medication), Indometacine ethyl ester (3Db, anti-inflammatory drug) and Fennofibrat (3Eb, a drug against cardiovascular disease) demonstrates the potential of this reaction for the derivatization of bioactive molecules and highlights the scope and applicability of the methodology in a pharmaceutical context. Notable limitations are aldehyde, acid or primary amine functionalities (see SI).

The substrate scope with regards to the thiol was evaluated next, with a focus on the previously challenging tertiary thiols (Table 4). Ethyl-4-chlorobenzoate (1a) was used as standard electrophile. Primary, secondary and a variety of sterically challenging tertiary alkyl thiols were coupled providing the 
desired thioether in good to excellent yields. Functional groups such as ketone 3al, 3am and ester 3an were tolerated. Thiocholesterol as a large, bioactive model thiol could be converted to 3 ap in $72 \%$ yield. Moieties like amines and acid groups as well as aryl, benzyl and homobenzyl thiols were not tolerated so far. The inhibition by thiols containing an aryl moiety in certain distances from the sulfur atom might be explained by a bidentate coordination of these compounds, since arenes can act as ligands for $\mathrm{Ni}(0)$ species. ${ }^{12}$

Table 3. Substrate scope with respect to aryl chlorides ${ }^{a}$

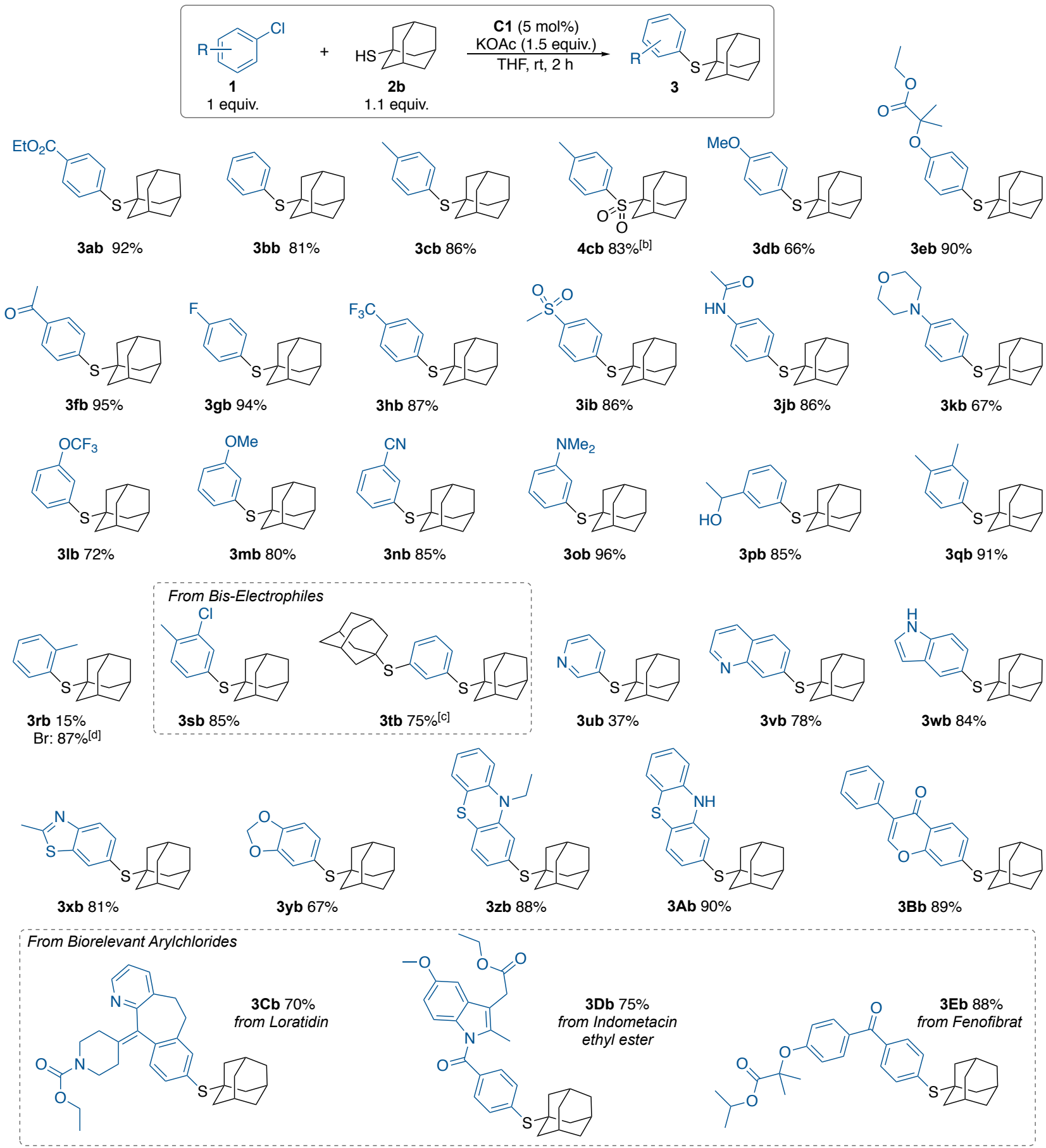

${ }^{a}$ Standard reaction conditions: 1 (1.0 equiv.), 2 b (1.1 equiv.), KOAc (1.5 equiv.), C1 (5 mol\%), THF (3 mL), rt, 2 h. Yields of isolated products unless stated otherwise. ${ }^{b}$ Isolated as sulfone after oxidation with $m$-CPBA (yield over two steps). ${ }^{c}$ With 2.1 equiv. of $\mathbf{2 b} .{ }^{d}$ GC-FID yields using pentadecane as internal standard.

Comparison of the reaction progress for representatives of primary (heptane-), secondary (cyclohexane-) and tertiary (adamantane-) thiols showed similar reaction rates but a significantly longer induction period for the tertiary adamantanethiol $\left(1^{\circ}, 2^{\circ} \approx 5 \mathrm{~min} ; 3^{\circ} \approx 15 \mathrm{~min}\right.$, Table 4$)$. This period might arise from the involvement of the thiol in the activation of $\mathbf{C 1}$, which will be discussed later. 
Table 4. Substrate scope with respect to alkyl thiols ${ }^{a}$

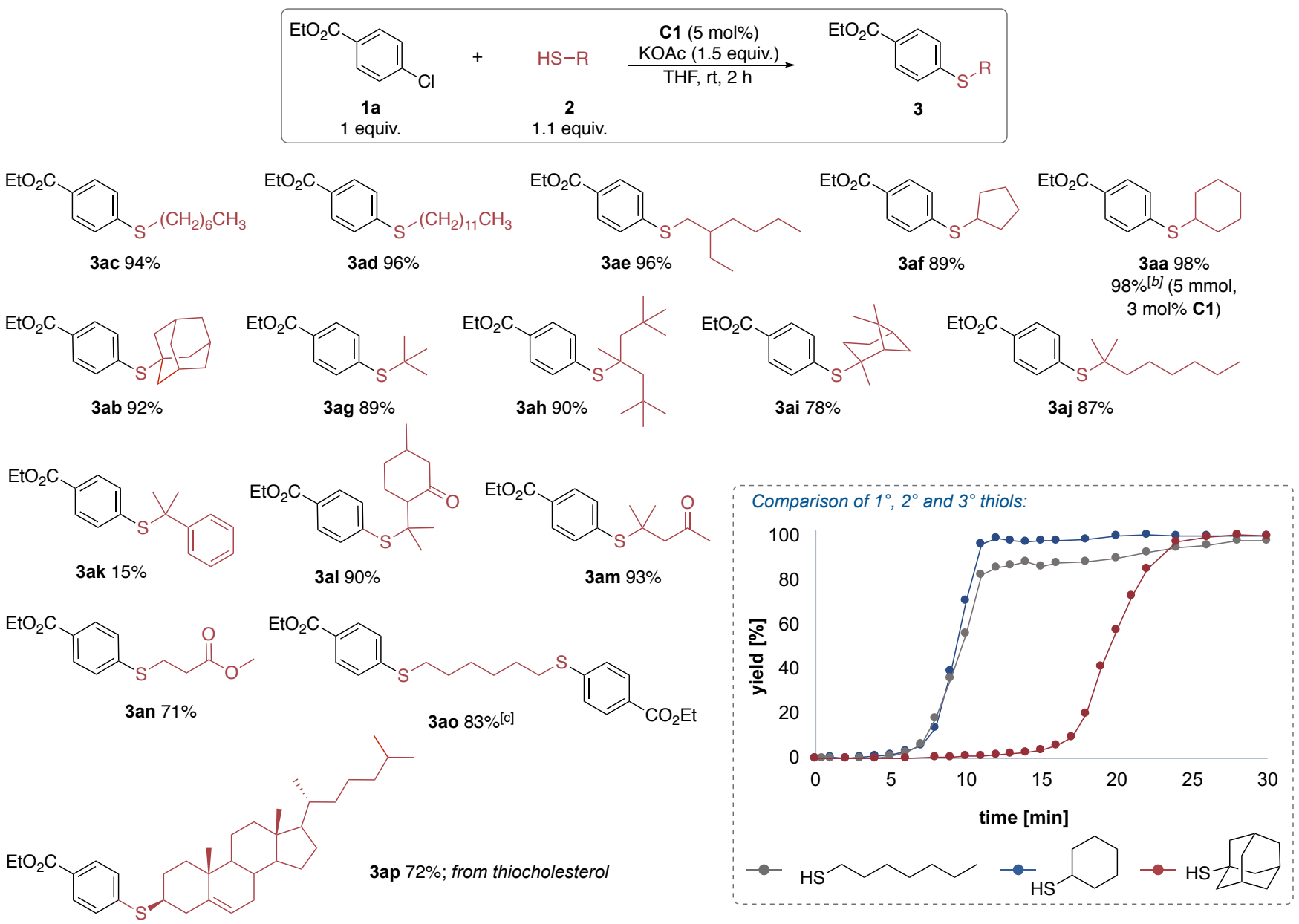

${ }^{a}$ Standard reaction conditions: 1a (1.0 equiv.), 2 (1.1 equiv.), KOAc (1.5 equiv.), C1 (5 mol\%), THF ( $\left.3 \mathrm{~mL}\right), \mathrm{rt}, 2 \mathrm{~h}$. Yields of isolated products unless stated otherwise. ${ }^{\mathrm{b}} 5 \mathrm{mmol}, \mathrm{C} 1$ ( $\left.3 \mathrm{~mol} \%\right)$, rt, $30 \mathrm{~min}$. ${ }^{\mathrm{c}} \mathrm{With} 2$ equiv. of $1 \mathrm{a}$.

Air stability and low cost of the reaction components are advantageous for the newly developed system. The reaction is operationally simple, and solids can be weighed under benchtop conditions before using inert conditions during the reaction. The coupling is fast $(30 \mathrm{~min}-2 \mathrm{~h})$ and takes place at room temperature. Upscaling of the reaction in the synthesis of $\mathbf{3 a a}$ while lowering the catalyst loading $(5 \mathrm{mmol}, 3 \mathrm{~mol} \% \mathrm{C1}$, $30 \mathrm{~min}$ ), as well as the ability to couple pharmaceutical compounds in good to excellent yields render this method interesting for possible industrial use. Another advantage is the high selectivity with little to no side reactions. Conversion and yield correlate for most substrates with max. 5\% difference and for unsuccessful reactions, the substrates could mostly be isolated and reused.

The identified reaction conditions are versatile and can be applied to a variety of electrophiles in addition to aryl chlorides. Phenyl bromide, iodide as well as triflate reacted in excellent yields (Scheme 2a). Interestingly, tosylates performed poorly. To assess the reactivity in greater detail, we subsequently undertook inter- and intramolecular competition experiments comparing the reactivity of different $\mathrm{C}-\mathrm{X}(\mathrm{X}=\mathrm{Cl}, \mathrm{Br}$, I, OTf, OTs) bonds. Intermolecular competition experiments between the electrophiles showed that every electrophile except tosylate reacted preferably to phenyl chloride, with the order PhOTf $>$
$\mathrm{PhBr}>\mathrm{PhI}>\mathrm{PhCl}$ when yields were compared after $2 \mathrm{~h}$ (Scheme 2b).

The reaction profiles of different electrophiles (Scheme 2c) showed an increase of the induction period from $\mathrm{PhOTf}<\mathrm{PhI}$ $<\mathrm{PhBr}<\mathrm{PhCl}$ and the reaction rate decreasing as followed: $\mathrm{PhOTf}>\mathrm{PhBr}>\mathrm{PhCl}>\mathrm{PhI}$, with phenyliodide as unexpected exception. Otherwise, the results roughly correlate with the expected ease of oxidative addition. The lower reactivity of $\mathrm{PhI}$ could be explained with Schoenebeck's ${ }^{13}$ observation that for nickel-catalyzed reactions with aryl iodides more off cycle $\mathrm{Ni}(\mathrm{I})$ species are formed and the catalysis is slower.

Intrigued by the intermolecular selectivity and inspired by literature reports on chemoselective $\mathrm{Pd}^{-14}$ and Ni-catalyzed ${ }^{15}$ couplings, we decided to examine if related transformations are possible with our system. Introducing substrates with two or more (pseudo)halide functionalities can enable selective, sequential reactions to generate complex functionalized target compounds or products with an intact and reactive functional group. Therefore, several 1,4-dielectrophilic substrates were subjected to intramolecular competition experiments (Scheme 3a). 
Scheme 2. Reactivity of electrophiles and intermolecular competition experiments $^{a}$

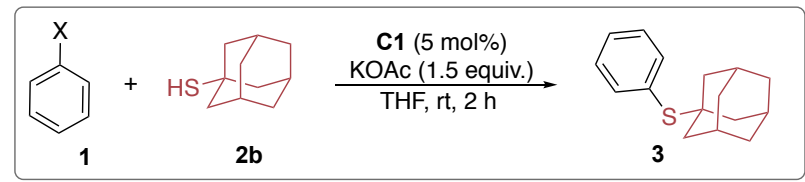

a) Comparison of electrophiles (1 equiv. of $\mathbf{1}(Y=H)+1.1$ equiv. of $\mathbf{2 b}$ )
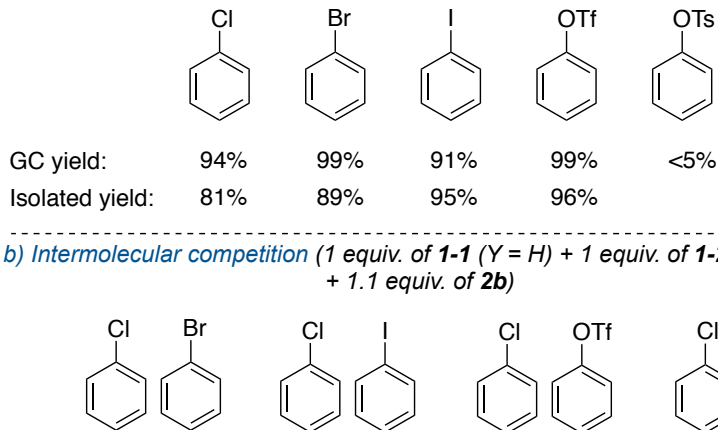

$99 \%$

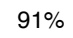

$99 \%$

$<5 \%$

$89 \% \quad 95 \% \quad 96 \%$

GC

conv.: $9 \% \quad 95 \%$

c) Reaction progress

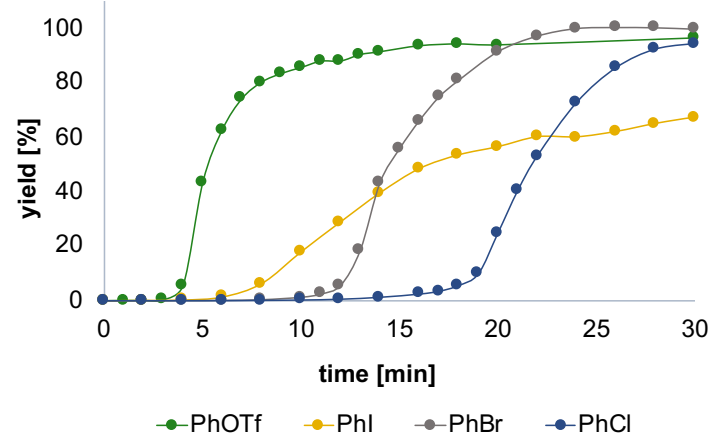

${ }^{a}$ GC-FID yields with pentadecane as internal standard.

No significant selectivity for monofunctionalization was observed between two different halides $\mathrm{C}-\mathrm{Cl}$ vs. $\mathrm{C}-\mathrm{Cl}, \mathrm{C}-\mathrm{Br}$ and $\mathrm{C}$-I. The difference in reactivity was not sufficient enough under standard conditions, although the more reactive $\mathrm{C}-\mathrm{X}$ bond was functionalized preferentially (only $\mathbf{3}-\mathbf{X}$ as monosubstituted product, no $\mathbf{3 - Y}$ can be observed), following the typical reactivity order of arylhalides toward oxidative addition with ArI $>\mathrm{ArBr}>\mathrm{ArCl}$. Unfortunately, the difunctionalized product 3-XY was obtained as well, explaining the lower conversion of electrophile $\mathbf{1}$.

In contrast, a higher chemodivergent selectivity could be observed in a C-OTf selective functionalization in the presence of $\mathrm{C}-\mathrm{Cl}$ bonds. Under standard reaction conditions monofunctionalization at the C-OTf site yielded thioether $\mathbf{3 F b}$ $(70 \%)$ in a mixture with difunctionalized product $(14 \%)$ and remaining starting material (16\%). Additionally, chemoselective couplings of $\mathrm{C}-\mathrm{Cl}(89 \%)$ and $\mathrm{C}-\mathrm{OTf}(94 \%)$ bonds in the presence of tosylate substitent, which is relatively inert under the employed reaction conditions, generated the corresponding monothioether in excellent isolated yields. In these cases, the GC-FID analysis of the crude mixture was hampered by detectability of the substrates and monosubstituted products, but no disubstituted compound nor the product of single $\mathrm{C}$-OTs sulfenylation were observed after isolation or on GC-MS. C-Cl selectivity in presence of C-OTs bonds is typical for $\mathrm{Ni}(0) .{ }^{16}$ The usefulness of the preferential activation of one particular $\mathrm{C}$-X bond was further demonstrated in two sequential C-S couplings of biselectrophilic substrates 1F and 1G (Scheme 3b). Surprisingly, tosylate could be converted under higher temperature with longer reaction time. The sequence was also successfully performed in one-pot fashion for both substrates. No additional catalyst was needed in the second step.

Scheme 3. Intramolecular competitions of biselectrophiles and application in sequential transformation ${ }^{a}$

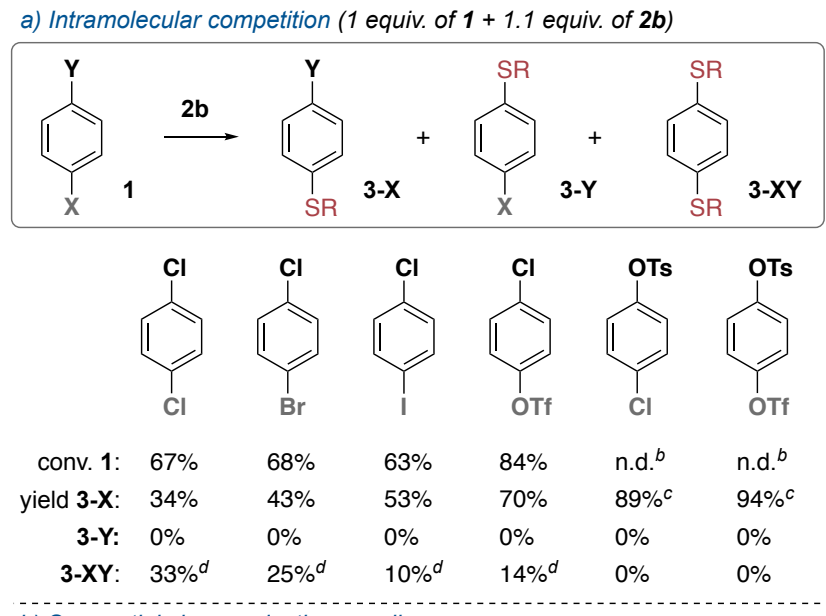

b) Sequential chemoselective coupling
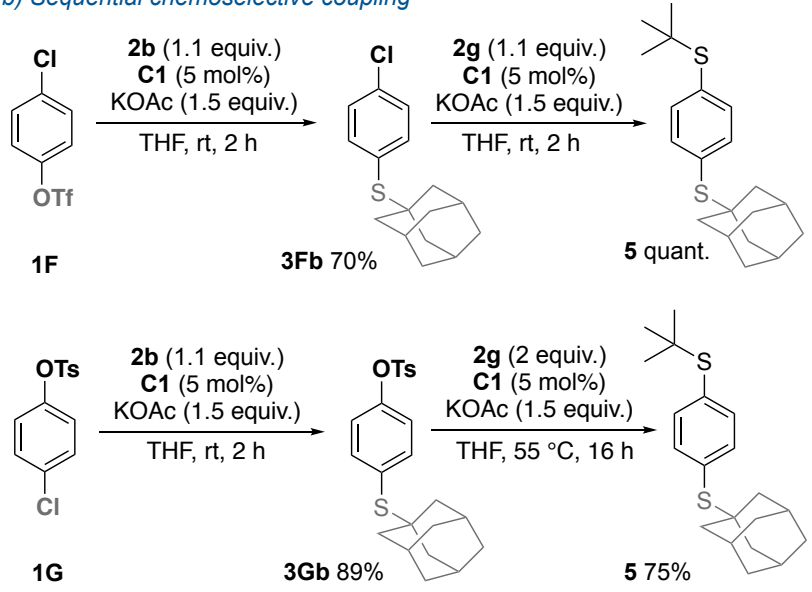

$3 \mathrm{~Gb} 89 \%$

$575 \%$

c) One-pot - sequential chemoselective coupling

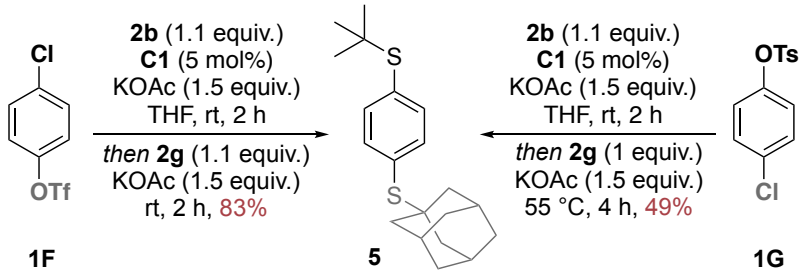

${ }^{a}$ GC-FID yields with pentadecane as internal standard, unless otherwise noted. ${ }^{b}$ Not determined due to detection difficulties by GC-FID. ${ }^{c}$ Isolated yields. ${ }^{d}$ Caluclated yields/GC-MS.

Next, we pursued mechanistic investigations of our catalytic reaction. Several experiments with radical scavengers (2 equiv.) were performed (see SI, Table S3). The reaction was suppressed in the presence of TEMPO (2,2,6,6-tetramethylpiperidinyloxyl) and galvinoxyl radical, which are also known to react directly with $\mathrm{Ni}(0)$ species. ${ }^{17}$ On the other hand, the reactions with BHT (butylated hydroxytoluene) and 9,10-dihydroantracene 
proceeded smoothly, providing $82 \%$ and $85 \%$ yields of thioether product, respectively. These observations as well as the lack of paramagnetic signals in NMR experiments (Figures 3,4 ) lead to the assumption that a 2-electron mechanism with a $\mathrm{Ni}(0) / \mathrm{Ni}(\mathrm{II})$ catalytic cycle is more likely. Cycles proceeding via alternative pathways, including single electron transfer steps cannot be ruled out completely, but they were not further considered.

In order to better understand the mechanism and the unique role the acetate plays, ${ }^{18}$ we performed DFT computations with the ORCA 4 electronic structure code. ${ }^{19}$ All structures were optimized with the B3LYP(VWN-3) hybrid density functional $^{20}$ in combination with Grimme's D3-disperision correction (with zero-damping) ${ }^{21}$ and a def2-SVP basis set, ${ }^{22}$ which treats all electrons explicitly (without an effective core potential). Furthermore, the electronic energies were refined by computing M06-L single point energies ${ }^{23}$ with the prodigious def2-QZVPP basis set and solvation effects were accounted for implicitly using the SMD model ${ }^{24}$ with THF as a solvent. Comparable levels of theory have previously been employed for the computational assessment of other Ni-catalyzed reactions. ${ }^{7 \mathrm{~b}}$ The obtained results are displayed in Figure 1.

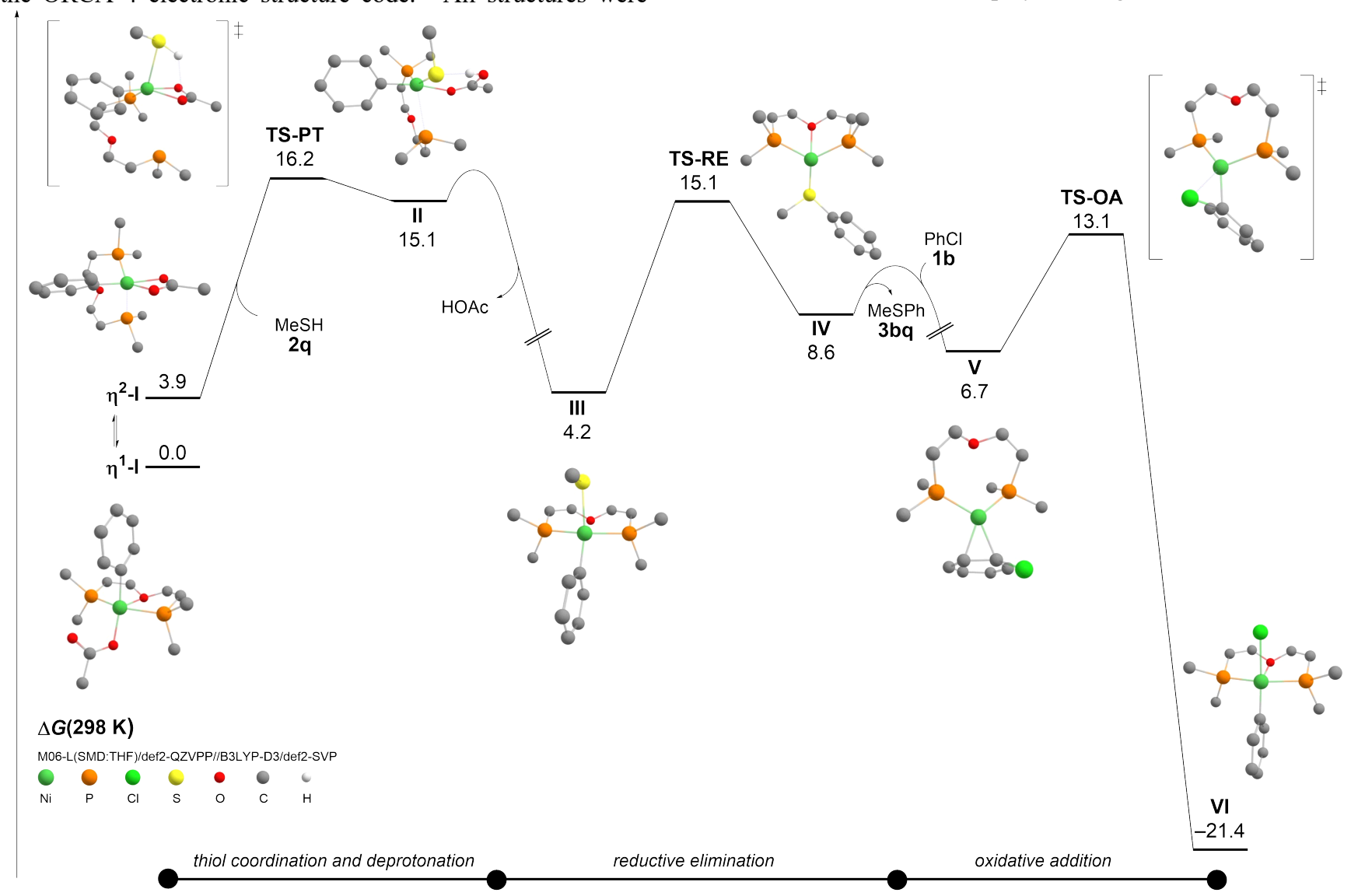

Figure 1. Free energy surface of the Ni-catalyzed cross-coupling reaction with methanethiol as a model nucleophile and chlorobenzene as the electrophile at the M06-L(SMD:THF)/def2-QZVPP//B3LYP-D3/def2-SVP level of theory. Only selected atoms of the Xantphos ligand are displayed and all carbon-bound hydrogens are omitted for clarity.

We were particularly interested in the role of the acetate both during the activation of the one-component $\mathrm{Ni}(\mathrm{II})$ precatalyst $\mathbf{C 1}$ and during the active catalytic cycle. $\mathbf{C 1}$ and the on-cycle oxidative addition product VI have a similar structural motive [LNi(II)ArCl], therefore activation of the catalyst and on-cycle catalysis share the same steps. Assuming the involvement of the metal during the deprotonation step and ligand exchange, Ni(II) complexes with acetate as a ligand were optimized. ${ }^{25}$ Two isomeric complexes, $\eta^{1}-\mathbf{I}$ and $\eta^{2}-\mathbf{I}$ [LNi(II)ArOAc] were localized, in which the acetate acts as a mono- and bidentate ligand, respectively. The $\eta^{1}-\mathbf{I}$ complex roughly assumes a distorted square-pyramidal geometry, in which both phosphorus atoms occupy equatorial positions across from each other at almost equal distances $(\sim 2.2 \AA)$, while the oxygen atom of Xantphos sits in the apical position. In contrast, this oxygen atom is unbound in the $3.9 \mathrm{kcal} \mathrm{mol}^{-1}$ less stable $\eta^{2}$-I complex and one of the phosphorus donors is less tightly bound at a distance of $2.4 \AA$. This opens the possibility for the thiol coupling partner to attack the metal center trans to the loosely bound phosphorus arm of the ligand. Using methanethiol as a model nucleophile, we were able to localize the transition state TS-PT at an energy of $16.2 \mathrm{kcal} \mathrm{mol}^{-1}$. The reactive mode of the transition state mainly corresponds to a contraction of the $\mathrm{Ni}-\mathrm{S}$ distance and an elongation of one of the $\mathrm{Ni}-\mathrm{O}$ bonds to the acetate. As confirmed with the help of intrinsic reaction coordinate (IRC) computations, the reactive motion is consistent with an insertion of the SH-moiety into an $\mathrm{Ni}-\mathrm{O}$ bond. However, we were unable to localize a minimum energy structure, in which the proton is still bound to the sulfur atom when thiolate and acetate are both coordinated to the nickel center suggesting that the transition state structure TS-PT corresponds to a metal-mediated proton transfer reaction. The resulting complex II is approximately square-planar and the second P-donor is remote from the coordination center $(3.2 \AA)$. Rebinding of the latter and dissociation of acetic acid in a not further elucidated order of events affords thiolate complex III 
[LNi(II)ArSMe] at an energy of $4.2 \mathrm{kcal} \mathrm{mol}^{-1}$. Therefore, the generation of thiolate complex III is modestly uphill but provides the possibility of product formation. The presumably interfering production of phenyl acetate by reductive elimination in $\mathbf{I}$ is not competitive since this process is associated with a prohibitive activation barrier of $44.0 \mathrm{kcal} \mathrm{mol}^{-1}$. However, the reductive elimination of the thioether product $\mathbf{3 b q}$ from complex III is activated by only $10.9 \mathrm{kcal} \mathrm{mol}^{-1}$ in another uphill reaction step. The thioether is initially still bound to the resulting $\mathrm{Ni}(0)$ complex $\mathbf{I V}$, but can be replaced by the chlorobenzene (1b). From there, facile oxidative addition under formation of complex VI provides sizable $28.1 \mathrm{kcal} \mathrm{mol}^{-1}$ of driving force to the reaction. The generation of complex I from VI and potassium acetate is difficult to describe computationally since it might involve the precipitation of potassium chloride in a salt metathesis reaction.

The corresponding proposed catalytic cycle is depicted in Scheme 4. After activation of precatalyst C1, generation of the active $\mathrm{Ni}(0)$ species (shown without the coordinated electrophile) and oxidative addition of the aryl halide, the intermediate VI is formed. It further undergoes a ligand exchange with potassium acetate generating $\mathbf{I}$ and precipitating $\mathrm{KCl}$ via salt metathesis. Subsequent acetate promoted deprotonation of the metal precoordinated thiol leads to intermediate III [LNi(II)ArSR]. This step (via intermediate II) is analogous to the CMD (concerted metalation-deprotonation) mechanism occurring in $\mathrm{C}$-H activation processes. ${ }^{26}$ Finally, III undergoes reductive elimination to yield the product and to regenerate the active $\mathrm{Ni}(0)$ catalyst.

Scheme 4. Postulated mechanism via acetate-assisted catalysis
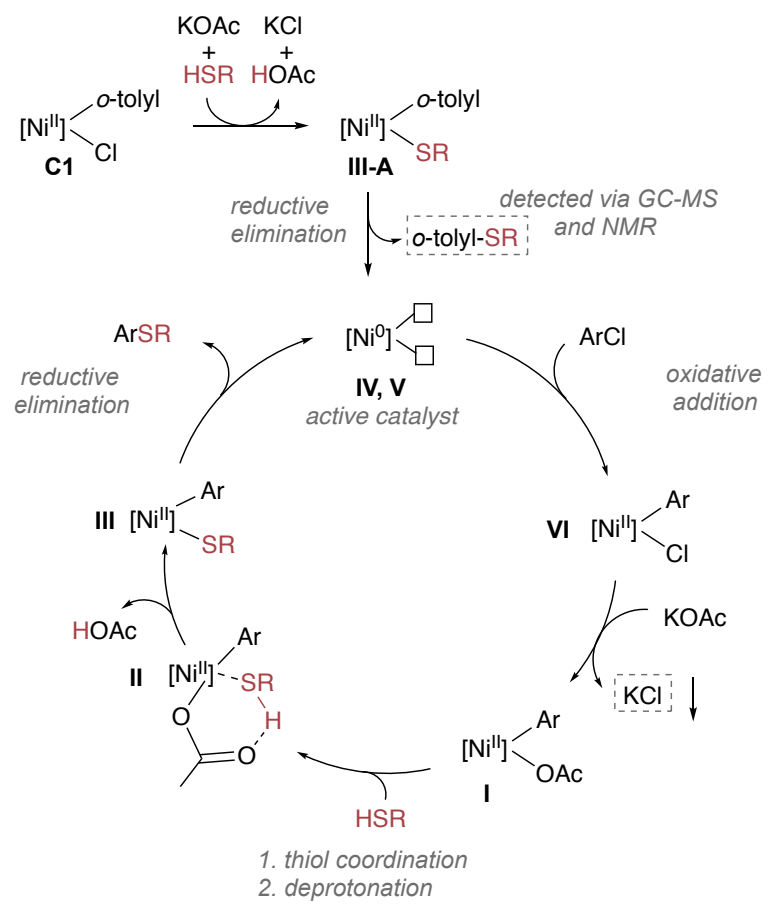

Several kinetic studies were conducted with electronic modifications of the electrophile (aryl chloride) and ligand, as well as steric modifications of the nucleophile (thiol) in order to analyze and compare initial periods, reaction rates and overall yields. The reaction profiles of varying thiols are depicted within Table 4. Similar reaction rates for primary, secondary (both $\left.\mathrm{k}_{r e l}=0.95\right)$ and tertiary thiols $\left(\mathrm{k}_{\mathrm{rel}}=1.0\right.$, see SI) indicate that the thiol is not relevant during the rate determining step or that its steric adaptations do not have any influence. However, a significantly longer initial period was observed for the tertiary thiol $\left(1^{\circ}, 2^{\circ}=5 \mathrm{~min} .3^{\circ}=15 \mathrm{~min}\right.$.), which can be explained through the involvement of thiol during the activation of precatalyst C1. Due to the ortho-substituent on the aryl coordinated to nickel in $\mathbf{C 1}$, an increase in steric strain could disfavor the formation of III-A [LNi(II)ArSR], especially with a tertiary thiol. Low yield observed for the ortho-methyl substituted arylchloride 3rb, in which the on-cycle intermediate III equals the activation intermediate III-A supports this theory.

Another hint supporting the hypothesis that the activation of C1 is responsible for an increase of the initial period is the use of $\mathrm{Ni}(\mathrm{cod})_{2}$ and Xanthphos as catalyst system, for which only a short induction period ( $<2 \mathrm{~min}$, Figure $2 \mathrm{c}$ in grey) was observed. The thiol is not involved in the in-situ generation of the active catalyst from a nickel( 0$)$ source.

In order to gain further insight into the mechanism and rate limiting step, Hammett studies were performed analyzing the influence of varying substituents on the ligand and electrophile on the reaction rate after the induction period (Figure 2, see SI section 6.1). ${ }^{27}$ The series of experiments with modified aryl chlorides ( $p$-OMe, $p$-Me, $p$ - $\left.\mathrm{H} p-\mathrm{CO}_{2} \mathrm{Et}, p-\mathrm{CF}_{3}\right)$ showed an impact of electronic properties on the reaction rate. Excluding the $\mathrm{CF}_{3}$-substituent, a linear correlation with the $\sigma_{\mathrm{p}}$ Hammett constant was observed $\left(\rho=0.46, \mathrm{R}^{2}=0.96\right)$ indicating that electron-withdrawing substituents increase the reaction rate to a specific point. The low $\rho$ value is in agreement with the DFT calculation, indicating that the oxidative addition is not the rate determining step. However, the reaction rate decreased for highly electron deficient trifluoromethyl-substituted substrate ( $\rho=-3.71)$. This indicates a change in mechanism, the rate determining step or different overall contributions.

The second Hammett study included adaptations of the electronic properties of the Xantphos ligand ( $p$-OMe, $p$-Me, $p$ - $\left.\mathrm{H}, p-\mathrm{CF}_{3}\right)$, which were tested with $\mathrm{Ni}(\operatorname{cod})_{2}$ as catalyst precursor via in-situ catalysis (Figure $2 \mathrm{c}, \mathrm{d}$ ). Electron-donating substituents on the ligand increased the reaction rate $(\rho=1.68$, $\mathrm{R}^{2}=0.83$ ), but the $p-\mathrm{CF}_{3}$-substituted ligand did not yield any product. Electron-donating ligands are known to stabilize higher oxidation states and promote the oxidative addition, ${ }^{28}$ but the interpretation is complicated due to multiple factors. The reaction performed with defined catalyst $\mathbf{C} 1$ is faster compared to the Xanthphos/ $\mathrm{Ni}(0)$ system. The lower reaction rate for $\mathrm{Ni}(\operatorname{cod})_{2}$ can be explained by the presence of cod, which was found to suppress oxidative addition during catalysis by coordinating and stabilizing the active $\mathrm{Ni}(0)$ catalyst rendering it less reactive. ${ }^{7 b, 29}$ Therefore the result of the Hammett analysis with $\mathrm{Ni}(\operatorname{cod})_{2}$ as nickel source might not be completely adaptable to our catalytic system, as the additional cod might change rates of the elemental steps and disfavor the oxidative addition. 


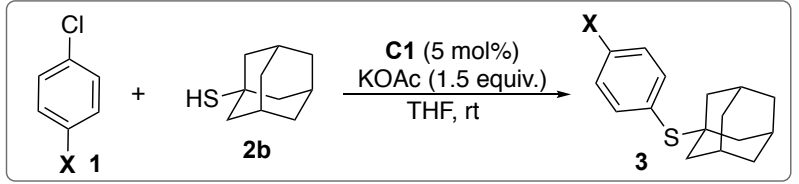

a) Arylchlorides: Kinetic Profiles

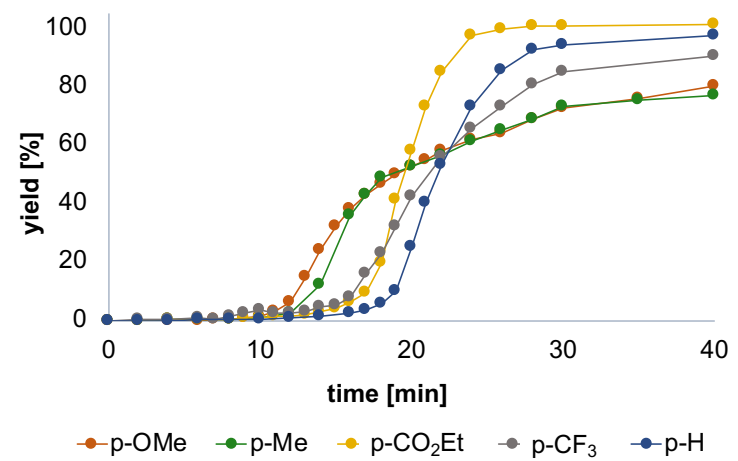

b) Arylchlorides: Hammett Analysis

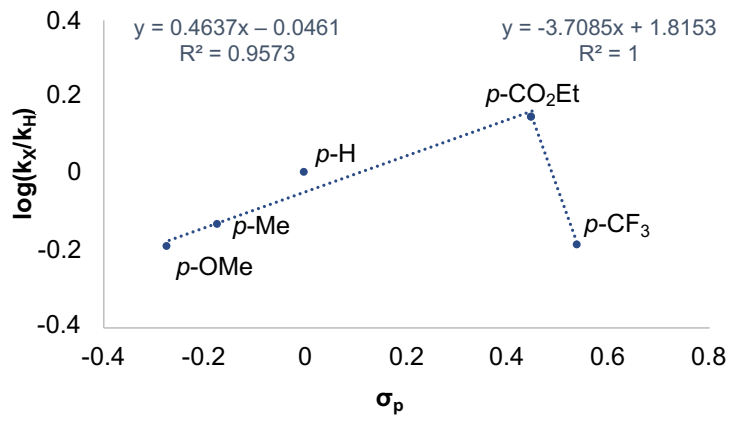

Figure 2. Kinetic and Hammett analysis. For reaction conditions, see SI.

To gain further insight into the mechanism, the standard reaction of $\mathbf{1 a}$ with $\mathbf{2 b}$ was followed by ${ }^{31} \mathrm{P}\{\mathrm{H}\}$ NMR (Figure 3 , SI section 6.2). After 5 minutes, signals of the employed precatalyst $\mathbf{C 1}$ (two different geometries, 6.55 and $1.43 \mathrm{ppm}$ ), free Xantphos (-18.20 ppm) and a new signal at $7.02 \mathrm{ppm}$ were detected, which can be assigned to the oxidative addition intermediate VI [ $\mathrm{LNiArCl}$ ]. The signal could be reproduced by an isolated complex from a mixture of $\mathrm{Ni}(\mathrm{cod})$, Xantphos and 1 a (Figure 3-2). After about 30 minutes, two broad doublets appeared at 9.31 and $8.24 \mathrm{ppm}$, presumably the $\mathrm{Ni}$ (Xanthphos) ${ }_{2}$ complex. The signal was reproduced by the addition of $\mathrm{Ni}(\operatorname{cod})_{2}$ and 2 equiv. of Xantphos (Figure 3-7). The complex has not yet been characterized in the literature, but it was previously identified as a catalyst sink. ${ }^{30}$ Corresponding data for the analogous Pd complex is known from the literature and shows similar signals. ${ }^{31}$

Crystallization of the catalytic intermediates was not successful, yet. However, we were able to follow and compare the formation of a series of oxidative addition complexes VI $[\mathrm{LNiArCl}]$ in the catalytic transformation of three electron-poor aryl chlorides (Figure 4). Variation of para-substituents on the aryl chloride for the on-cycle generation of the oxidative addition product shows a shift in the ${ }^{31} \mathrm{P}\{\mathrm{H}\}$ signals correlating to the Hammett value $\left(\mathrm{CO}_{2} \mathrm{Et} \sigma_{p}=+0.45,7.02 \mathrm{ppm} ; \mathrm{CF}_{3} \sigma_{p}=\right.$ $\left.+0.54,7.47 \mathrm{ppm} ; \mathrm{SO}_{2} \mathrm{Me} \sigma_{p}=+0.73,7.69 \mathrm{ppm}\right)$. These signals could be reproduced in a reaction of $\mathrm{Ni}(\mathrm{cod})_{2}$, Xantphos and the

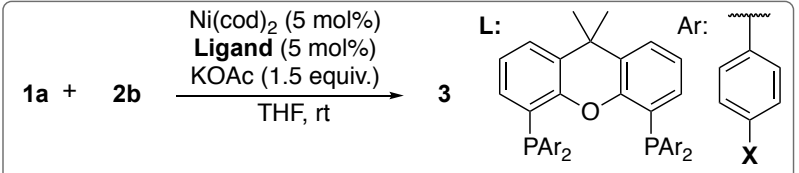

c) Ligands: Kinetic Profiles

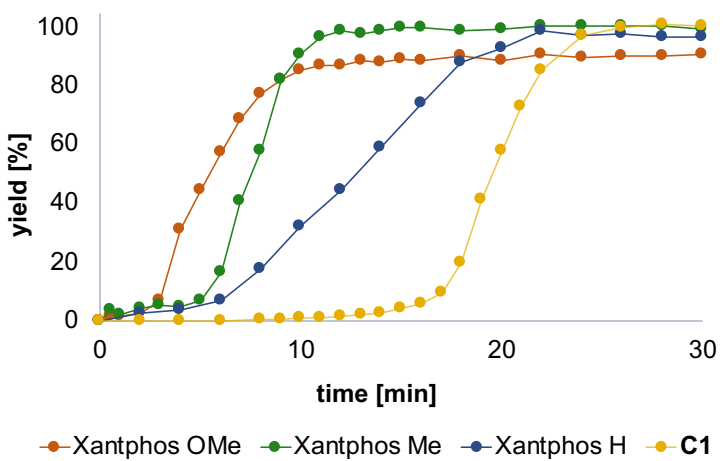

d) Ligands: Hammett Analysis

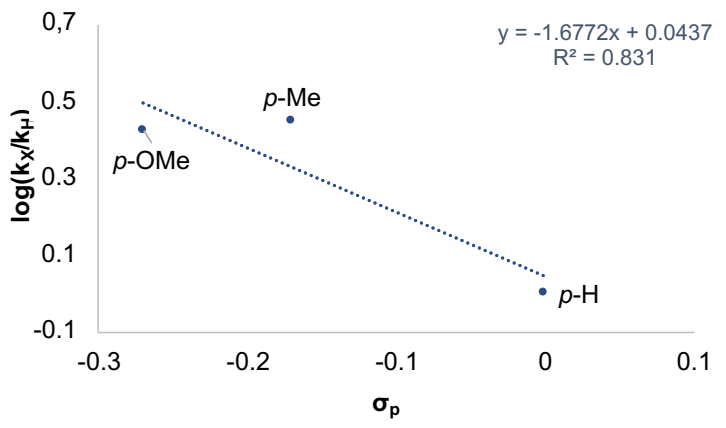

corresponding aryl chloride. The experiments suggest that the oxidative addition product is the resting state of the catalytic cycle, which is in line with previous observations and our DFT computations. (for further NMR spectra, see SI section 6.2.).

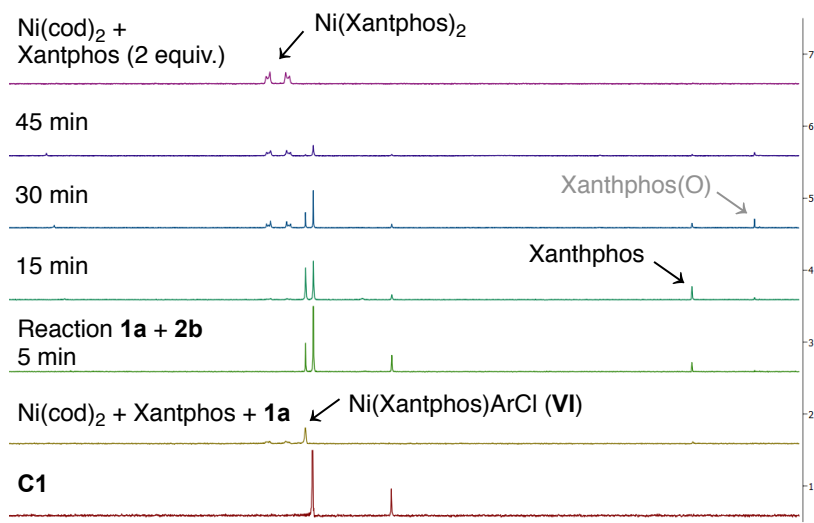

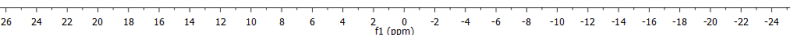

Figure 3. ${ }^{31} \mathrm{P}\{\mathrm{H}\}$ NMR spectra for the reaction progress of a standard reaction with $\mathbf{1} \mathbf{a}$ and $\mathbf{3 b}$ (3-6). With additional comparison spectra $(1,2,7)$. 

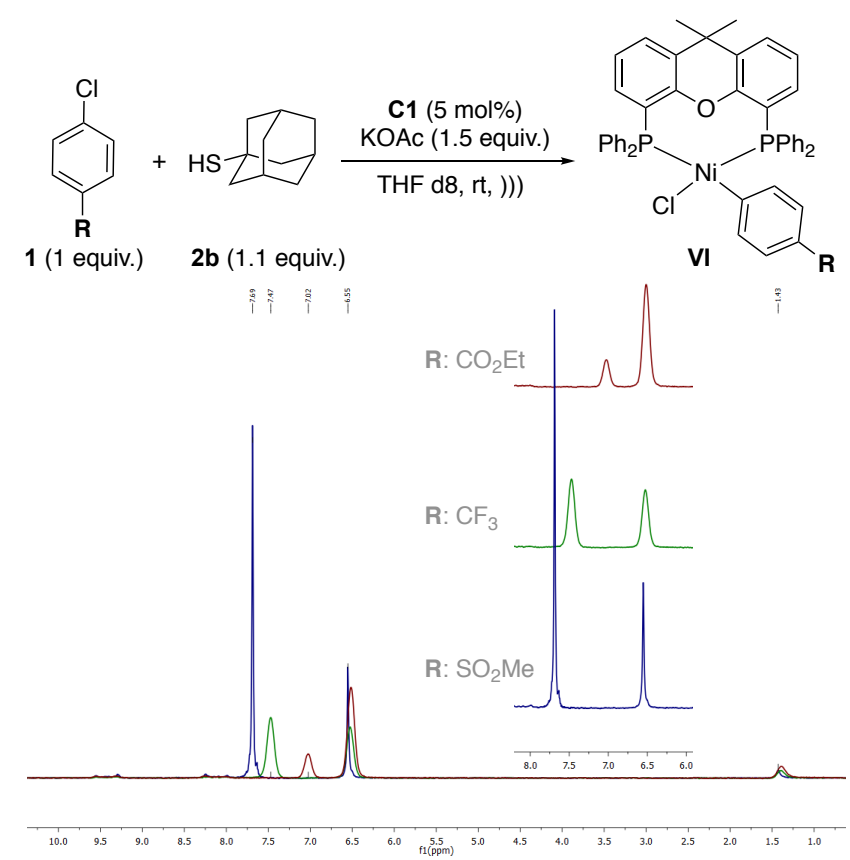

Figure 4. ${ }^{31} \mathrm{P}\{\mathrm{H}\}$ NMR spectra of oxidative addition intermediates detected in the transformation of various electrophiles. Signals at $6.55 \mathrm{ppm}$ and $1.43 \mathrm{ppm}$ correspond to $\mathbf{C} \mathbf{1}$.

\section{CONCLUSION}

An operationally simple and mild nickel-catalyzed coupling of aryl chlorides with aliphatic thiols at room temperature was developed. Key feature is the combination of a defined air stable $\mathrm{Ni}$ (II) precatalyst and potassium acetate as base, without the need for further additives. A large variety of functional groups was tolerated, and complex pharmaceutically relevant compounds were functionalized. Chemoselective coupling of tertiary thiols with triflates in the presence of $\mathrm{C}-\mathrm{Cl}$ and $\mathrm{C}-\mathrm{OTs}$ bonds, as well as with chlorides in presence of C-OTs bonds was achieved. The conducted kinetic and NMR studies as well as DFT computations support a $\mathrm{Ni}(0) / \mathrm{Ni}$ (II) catalytic cycle with the oxidative addition product as resting state and acetate playing a key role in the formation of a thiolate complex via internal deprotonation.

\section{ASSOCIATED CONTENT}

\section{Supporting Information}

The Supporting Information is available free of charge on the ACS Publications website.

General procedures, analytical data, NMR spectra (PDF), computational data.

\section{AUTHOR INFORMATION}

\section{Corresponding Authors}

* Ivana Fleischer: Institute of Organic Chemistry, Faculty of Science and Mathematics, Eberhard-Karls University Tübingen, Auf der Morgenstelle 18, 72076 Tübingen, Germany; ivana.fleischer@uni-tuebingen.de * J. Philipp Wagner: Institute Organic Chemistry, Faculty of Science and Mathematics, Eberhard-Karls University Tübingen, Auf der Morgenstelle 18, 72076 Tübingen, Germany; philipp.wagner@orgchem.uni-tuebingen.de

\section{Author Contributions}

The manuscript was written through contributions of all authors. All authors have given approval to the final version of the manuscript.

\section{ACKNOWLEDGMENT}

We thank M. Abbas, A. Huber and S. Clewing for their synthetic contributions to the project during research internships and the analytics department of the University of Tübingen for their excellent work. Financial support from the University of Tübingen and FCI (Liebig Fellowship J. P. W.) is gratefully acknowledged. J. P. W. is grateful to Prof. Holger Bettinger for his generous support.

\section{REFERENCES}

1. Migita, T.; Shimizu, T.; Asami, Y.; Shiobara, J.-i.; Kato, Y.; Kosugi, M., The Palladium Catalyzed Nucleophilic Substitution of Aryl Halides by Thiolate Anions. Bull. Chem. Soc. Jpn. 1980, 53, 13851389.

2. (a) Scott, K. A.; Njardarson, J. T., Analysis of US FDAApproved Drugs Containing Sulfur Atoms. Top. Curr. Chem. 2018, 376, 5; (b) Hill Jr., H. W.; Brady, D. G., Properties, environmental stability, and molding characteristics of polyphenylene sulfide. Polym. Eng. Sci. 1976, 16, 831-835; (c) Hilton, H. W.; Nomura, N. S.; Yauger, W. L.; Kameda, S. S., Absorption, translocation, and metabolism of metribuzin (BAY-94337) in sugarcane. J. Agric. Food Chem. 1974, 22, 578-582.

3. For selected examples, see: (a) Li, G. Y., The First Phosphine Oxide Ligand Precursors for Transition Metal Catalyzed Cross-Coupling Reactions: $\mathrm{C}-\mathrm{C}, \mathrm{C}-\mathrm{N}$, and $\mathrm{C}-\mathrm{S}$ Bond Formation on Unactivated Aryl Chlorides. Angew. Chem. Int. Ed. 2001, 40, 15131516; (b) Fernández-Rodríguez, M. A.; Shen, Q.; Hartwig, J. F., A General and Long-Lived Catalyst for the Palladium-Catalyzed Coupling of Aryl Halides with Thiols. J. Am. Chem. Soc. 2006, 128, 2180-2181; (c) Murata, M.; Buchwald, S. L., A general and efficient method for the palladium-catalyzed cross-coupling of thiols and secondary phosphines. Tetrahedron 2004, 60, 7397-7403.

4. For selected examples, see: (a) Chekal, B.; Damon, D.; LaFrance, D.; Leeman, K.; Mojica, C.; Palm, A.; St. Pierre, M.; Sieser, J.; Sutherland, K.; Vaidyanathan, R.; Van Alsten, J.; Vanderplas, B.; Wager, C.; Weisenburger, G.; Withbroe, G.; Yu, S., Development of the Commercial Route for the Manufacture of a 5-Lipoxygenase Inhibitor PF-04191834. Org. Process Res. Dev. 2015, 19, 1944-1953; (b) Chekal, B. P.; Guinness, S. M.; Lillie, B. M.; McLaughlin, R. W.; Palmer, C. W.; Post, R. J.; Sieser, J. E.; Singer, R. A.; Sluggett, G. W.; Vaidyanathan, R.; Withbroe, G. J., Development of an Efficient PdCatalyzed Coupling Process for Axitinib. Org. Process Res. Dev. 2014, 18, 266-274.

5. For selected reviews on nickel catalysis, see: (a) Ananikov, V. P., Nickel: The "Spirited Horse" of Transition Metal Catalysis. ACS Catal. 2015, 5, 1964-1971; (b) Tasker, S. Z.; Standley, E. A.; Jamison, T. F., Recent advances in homogeneous nickel catalysis. Nature 2014, 509, 299-309; (c) Diccianni, J. B.; Diao, T., Mechanisms of NickelCatalyzed Cross-Coupling Reactions. Trends Chem. 2019, 1, 830-844.

6. (a) Kentaro, T., Nickel(0)-catalyzed Synthesis of Diaryl Sulfides from Aryl Halides and Aromatic Thiols. Chem. Lett. 1987, 16, 2221-2224; (b) Zhang, Y.; Ngeow, K. C.; Ying, J. Y., The First NHeterocyclic Carbene-Based Nickel Catalyst for $\mathrm{C}-\mathrm{S}$ Coupling. Org. Lett. 2007, 9, 3495-3498; (c) Iglesias, M. J.; Prieto, A.; Nicasio, M. C., Well-Defined Allylnickel Chloride/N-Heterocyclic Carbene [(NHC)Ni(allyl)Cl] Complexes as Highly Active Precatalysts for C N and C S Cross-Coupling Reactions. Adv. Synth. Catal. 2010, 352, 1949-1954; (d) Martin, A. R.; Nelson, D. J.; Meiries, S.; Slawin, A. M. Z.; Nolan, S. P., Efficient $\mathrm{C}-\mathrm{N}$ and $\mathrm{C}-\mathrm{S}$ Bond Formation Using the Highly Active [Ni(allyl)Cl(IPr*OMe)] Precatalyst. Eur. J. Org. Chem. 2014, 2014, 3127-3131; (e) Cristau, H. J.; Chabaud, B.; Chêne, A.; Christol, H., Synthesis of Diaryl Sulfides by Nickel(II)-Catalyzed Arylation of Arenethiolates. Synthesis 1981, 1981, 892-894; (f) Talukder, M. M.; Miller, J. T.; Cue, J. M. O.; Udamulle, C. M.; 
Bhadran, A.; Biewer, M. C.; Stefan, M. C., Mono- and Dinuclear $\alpha-$ Diimine Nickel(II) and Palladium(II) Complexes in C-S CrossCoupling. Organometallics 2021, 40, 83-94; (g) Yu, T.-Y.; Pang, H.; Cao, Y.; Gallou, F.; Lipshutz, B. H., Safe, Scalable, Inexpensive, and Mild Nickel-Catalyzed Migita-Like $\mathrm{C}-\mathrm{S}$ Cross-Couplings in Recyclable Water. Angew. Chem. Int. Ed. 2021, 60, 3708-3713; (h) Liu, D.; Ma, H. X.; Fang, P.; Mei, T. S., Nickel-Catalyzed Thiolation of Aryl Halides and Heteroaryl Halides through Electrochemistry. Angew Chem Int Ed Engl 2019, 58, 5033-5037.

7. $\quad$ (a) Jones, K. D.; Power, D. J.; Bierer, D.; Gericke, K. M.; Stewart, S. G., Nickel Phosphite/Phosphine-Catalyzed C-S CrossCoupling of Aryl Chlorides and Thiols. Org. Lett. 2018, 20, 208-211; (b) Yin, G.; Kalvet, I.; Englert, U.; Schoenebeck, F., Fundamental Studies and Development of Nickel-Catalyzed Trifluoromethylthiolation of Aryl Chlorides: Active Catalytic Species and Key Roles of Ligand and Traceless MeCN Additive Revealed. $J$. Am. Chem. Soc. 2015, 137, 4164-4172; (c) Martín, M. T.; Marín, M.; Maya, C.; Prieto, A.; Nicasio, M. C., Ni(II) Precatalysts Enable Thioetherification of (Hetero)Aryl Halides and Tosylates and Tandem C-S/C-N Couplings. Chem. Eur. J. 2021, 27, 12320-12326.

8. Gehrtz, P. H.; Geiger, V.; Schmidt, T.; Srsan, L.; Fleischer, I., Cross-Coupling of Chloro(hetero)arenes with Thiolates Employing a $\mathrm{Ni}(0)$-Precatalyst. Org. Lett. 2019, 21, 50-55.

9. (a) Guan, P.; Cao, C.; Liu, Y.; Li, Y.; He, P.; Chen, Q.; Liu, G.; Shi, Y., Efficient nickel/N-heterocyclic carbene catalyzed C-S cross-coupling. Tetrahedron Lett. 2012, 53, 5987-5992; (b) Xu, X.-B.; Liu, J.; Zhang, J.-J.; Wang, Y.-W.; Peng, Y., Nickel-Mediated Interand Intramolecular C-S Coupling of Thiols and Thioacetates with Aryl Iodides at Room Temperature. Org. Lett. 2013, 15, 550-553; (c) Venkanna, G. T.; Arman, H. D.; Tonzetich, Z. J., Catalytic C-S CrossCoupling Reactions Employing Ni Complexes of Pyrrole-Based Pincer Ligands. ACS Catal. 2014, 4, 2941-2950; (d) Jouffroy, M.; Kelly, C. B.; Molander, G. A., Thioetherification via Photoredox/Nickel Dual Catalysis. Org. Lett. 2016, 18, 876-879; (e) Oderinde, M. S.; Frenette, M.; Robbins, D. W.; Aquila, B.; Johannes, J. W., Photoredox Mediated Nickel Catalyzed Cross-Coupling of Thiols With Aryl and Heteroaryl Iodides via Thiyl Radicals. J. Am. Chem. Soc. 2016, 138, 1760-1763; (f) Guo, F.-J.; Sun, J.; Xu, Z.-Q.; Kuhn, F. E.; Zang, S.-L.; Zhou, M.D., C-S cross-coupling of aryl halides with alkyl thiols catalyzed by insitu generated nickel(II) N-heterocyclic carbene complexes. Catal. Commun. 2017, 96, 11-14; (g) Jones, K. D.; Power, D. J.; Bierer, D.; Gericke, K. M.; Stewart, S. G., Nickel Phosphite/Phosphine-Catalyzed C-S Cross-Coupling of Aryl Chlorides and Thiols. Org. Lett. 2018, 20, 208-211; (h) Cavedon, C.; Madani, A.; Seeberger, P. H.; Pieber, B., Semiheterogeneous Dual Nickel/Photocatalytic (Thio)etherification Using Carbon Nitrides. Org. Lett. 2019, 21, 5331-5334; (i) Delcaillau, T.; Bismuto, A.; Lian, Z.; Morandi, B., Nickel-Catalyzed Inter- and Intramolecular Aryl Thioether Metathesis by Reversible Arylation. Angew. Chem., Int. Ed. 2020, 59, 2110-2114; (j) Rodriguez-Cruz, M. A.; Hernandez-Ortega, S.; Valdes, H.; Rufino-Felipe, E.; MoralesMorales, D., C-S cross-coupling catalyzed by a series of easily accessible, well defined $\mathrm{Ni}(\mathrm{II})$ complexes of the type [(NHC)Ni(Cp)(Br)]. J. Catal. 2020, 383, 193-198; (k) Talukder, M. M.; Miller, J. T.; Cue, J. M. O.; Udamulle, C. M.; Bhadran, A.; Biewer, M. C.; Stefan, M. C., Mono- and Dinuclear $\alpha$-Diimine Nickel(II) and Palladium(II) Complexes in C-S Cross-Coupling. Organometallics 2021，40, 83-94; (1) Isshiki, R.; Kurosawa, M. B.; Muto, K.; Yamaguchi, J., Ni-Catalyzed Aryl Sulfide Synthesis through an Aryl Exchange Reaction. J. Am. Chem. Soc. 2021, 143, 10333-10340.

10. Standley, E. A.; Smith, S. J.; Müller, P.; Jamison, T. F., A Broadly Applicable Strategy for Entry into Homogeneous Nickel(0) Catalysts from Air-Stable Nickel(II) Complexes. Organometallics 2014, 33, 2012-2018.

11. For catalysis using C1 catalyst, see: (a) Beattie, D. D.; Schareina, T.; Beller, M., A room temperature cyanation of (hetero)aromatic chlorides by an air stable nickel(II) XantPhos precatalyst and $\mathrm{Zn}(\mathrm{CN}) 2$. Org. Biomol. Chem. 2017, 15, 4291-4294; (b) Gehrtz, P. H.; Kathe, P.; Fleischer, I., Nickel-Catalyzed Coupling of Arylzinc Halides with Thioesters. Chem. Eur. J. 2018, 24, 87748778; for related Ni complexes, see: (c) McGuire, R. T.; Paffile, J. F. J.; Zhou, Y.; Stradiotto, M., Nickel-Catalyzed C-N Cross-Coupling of
Ammonia, (Hetero)anilines, and Indoles with Activated (Hetero)aryl Chlorides Enabled by Ligand Design. ACS Catal. 2019, 9, 9292-9297; (d) Morrison, K. M.; McGuire, R. T.; Ferguson, M. J.; Stradiotto, M., CgPhen-DalPhos Enables the Nickel-Catalyzed O-Arylation of Tertiary Alcohols with (Hetero)Aryl Electrophiles. ACS Catal. 2021, 11, 10878-10884.

12. Brauer, D. J.; Krueger, C., Bonding of aromatic hydrocarbons to nickel $(0)$. Structure of bis(tricyclohexylphosphine)(1,2-.eta.2-anthracene)nickel(0)-toluene. Inorg. Chem. 1977, 16, 884-891.

13. Kalvet, I.; Guo, Q.; Tizzard, G. J.; Schoenebeck, F., When Weaker Can Be Tougher: The Role of Oxidation State (I) in P- vs NLigand-Derived Ni-Catalyzed Trifluoromethylthiolation of Aryl Halides. ACS Catal. 2017, 7, 2126-2132.

14. (a) Scattolin, T.; Senol, E.; Yin, G.; Guo, Q.; Schoenebeck, F., Site-Selective $\mathrm{C}-\mathrm{S}$ Bond Formation at $\mathrm{C}-\mathrm{Br}$ over $\mathrm{C}-\mathrm{OTf}$ and $\mathrm{C}-\mathrm{Cl}$ Enabled by an Air-Stable, Easily Recoverable, and Recyclable Palladium(I) Catalyst. Angew. Chem. Int. Ed. 2018, 57, 12425-12429; (b) Keaveney, S. T.; Kundu, G.; Schoenebeck, F., Modular Functionalization of Arenes in a Triply Selective Sequence: Rapid $\mathrm{C}(\mathrm{sp} 2)$ and $\mathrm{C}(\mathrm{sp} 3)$ Coupling of $\mathrm{C}-\mathrm{Br}, \mathrm{C}-\mathrm{OTf}$, and $\mathrm{C}-\mathrm{Cl}$ Bonds Enabled by a Single Palladium(I) Dimer. Angew. Chem. Int. Ed. 2018, 57, 12573-12577.

15. (a) Reeves, E. K.; Entz, E. D.; Neufeldt, S. R., Chemodivergence between Electrophiles in Cross-Coupling Reactions. Chem. Eur. J. 2021, 27, 6161-6177; (b) Entz, E. D.; Russell, J. E. A.; Hooker, L. V.; Neufeldt, S. R., Small Phosphine Ligands Enable Selective Oxidative Addition of Ar-O over Ar-Cl Bonds at Nickel(0). J. Am. Chem. Soc. 2020, 142, 15454-15463.

16. Russell, J. E. A.; Neufeldt, S. R., C-O-Selective CrossCoupling of Chlorinated Phenol Derivatives. Synlett 2021, 32, 14841491.

17. Greaves, M. E.; Ronson, T. O.; Lloyd-Jones, G. C.; Maseras, F.; Sproules, S.; Nelson, D. J., Unexpected Nickel Complex Speciation Unlocks Alternative Pathways for the Reactions of Alkyl Halides with dppf-Nickel(0). ACS Catal. 2020, 10, 10717-10725.

18. Kalek, M.; Jezowska, M.; Stawinski, J., Preparation of Arylphosphonates by Palladium(0)-Catalyzed Cross-Coupling in the Presence of Acetate Additives: Synthetic and Mechanistic Studies. Adv. Synth. Catal. 2009, 351, 3207-3216.

19. Neese, F., Software Update: the ORCA Program System, Version 4.0. Wiley. Interdiscip. Rev. Comput. Mol. Sci. 2018, 8, e1327.

20. (a) Becke, A. D., Density-Functional Thermochemistry. III. The Role of Exact Exchange. J. Chem. Phys. 1993, 98, 5648-5652; (b) Stephens, P. J.; Devlin, F. J.; Chabalowski, C. F.; Frisch, M. J., Ab Initio Calculation of Vibrational Absorption and Circular Dichroism Spectra Using Density Functional Force Fields. J. Phys. Chem. 1994, 98, 11623-11627.

21. Grimme, S.; Antony, J.; Ehrlich, S.; Krieg, H., A Consistent and Accurate $\mathrm{Ab}$ Initio Parametrization of Density Functional Dispersion Correction (DFT-D) for the 94 Elements H-Pu. J. Chem. Phys. 2010, 132, 154104.

22. Weigend, F.; Ahlrichs, R., Balanced Basis Sets of Split Valence, Triple Zeta Valence and Quadruple Zeta Valence Quality for H to Rn: Design and Assessment of Accuracy. Phys. Chem. Chem. Phys. 2005, 7, 3297-3305.

23. Zhao, Y.; Truhlar, D. G., A New Local Density Functional for Main-Group Thermochemistry, Transition Metal Bonding, Thermochemical Kinetics, and Noncovalent Interactions. J. Chem. Phys. 2006, 125, 194101.

24. Marenich, A. V.; Cramer, C. J.; Truhlar, D. G., Universal Solvation Model Based on Solute Electron Density and on a Continuum Model of the Solvent Defined by the Bulk Dielectric Constant and Atomic Surface Tensions. J. Phys. Chem. B 2009, 113, 6378-6396.

25. Li, Z.; Zhang, S.-L.; Fu, Y.; Guo, Q.-X.; Liu, L., Mechanism of Ni-Catalyzed Selective $\mathrm{C}-\mathrm{O}$ Bond Activation in Cross-Coupling of Aryl Esters. J. Am. Chem. Soc. 2009, 131, 8815-8823.

26. For selected examples on CMD mechanism, see: (a) Stuart, D. R.; Fagnou, K., The Catalytic Cross-Coupling of Unactivated Arenes. Science 2007, 316, 1172-1175; (b) Gorelsky, S. I.; Lapointe, D.; Fagnou, K., Analysis of the Concerted Metalation-Deprotonation 
Mechanism in Palladium-Catalyzed Direct Arylation Across a Broad Range of Aromatic Substrates. J. Am. Chem. Soc. 2008, 130, 1084810849; (c) Bugaut, X.; Glorius, F., Palladium-Catalyzed Selective Dehydrogenative Cross-Couplings of Heteroarenes. Angew. Chem. Int. Ed. 2011, 50, 7479-7481; (d) Zhang, S.; Shi, L.; Ding, Y., Theoretical Analysis of the Mechanism of Palladium(II) Acetate-Catalyzed Oxidative Heck Coupling of Electron-Deficient Arenes with Alkenes: Effects of the Pyridine-Type Ancillary Ligand and Origins of the metaRegioselectivity. J. Am. Chem. Soc. 2011, 133, 20218-20229.

27. (a) Hansch, C.; Leo, A.; Taft, R. W., A survey of Hammett substituent constants and resonance and field parameters. Chem Rev 1991, 91, 165-195; (b) Hammett, L. P., The Effect of Structure upon the Reactions of Organic Compounds. Benzene Derivatives. J. Am. Chem. Soc. 1937, 59, 96-103.

28. Xiong, B.; Li, Y.; Wei, Y.; Kramer, S.; Lian, Z., Dual Nickel-/Palladium-Catalyzed Reductive Cross-Coupling Reactions between Two Phenol Derivatives. Org. Lett. 2020, 22, 6334-6338.
29. Bajo, S.; Laidlaw, G.; Kennedy, A. R.; Sproules, S.; Nelson, D. J., Oxidative Addition of Aryl Electrophiles to a Prototypical Nickel(0) Complex: Mechanism and Structure/Reactivity Relationships. Organometallics 2017, 36, 1662-1672.

30. Clevenger, A. L.; Stolley, R. M.; Staudaher, N. D.; Al, N.; Rheingold, A. L.; Vanderlinden, R. T.; Louie, J., Comprehensive Study of the Reactions Between Chelating Phosphines and $\mathrm{Ni}(\mathrm{cod}) 2$. Organometallics 2018, 37, 3259-3268.

31. Klingensmith, L. M.; Strieter, E. R.; Barder, T. E.; Buchwald, S. L., New Insights into Xantphos/Pd-Catalyzed C-N Bond Forming Reactions: A Structural and Kinetic Study. Organometallics 2006, 25, 82-91. 